\title{
Museums without Limits; COLLABORATION BETWEEN SWEDISH AND AFRICAN Museums
}

\section{Elisabet Olofsson}

"What can we Swedes and Africans, museum workers from different countries, worlds and cultures, learn from one another?

Museum workers from Benin, Kenya, Madagascar, Mozambique, Swaziland, Sweden, Tanzania, Zambia and Zimbabwe gather, and pool ideas and experience to shape the museum of the future." (Margareta Ekarv, Stockholm, Sweden, 1992. Text to the exhibition "Sharing Ideas")

Six years ago in May 1989 I met with colleagues from thirteen African and an equal number of Swedish museums for a four-day conference at one of Sweden's people's colleges.

"I was one of them. It was an overwhelming meeting. The theme of the conference was 'Death - a part of life' and, from the very beginning, our discussions dealt with the core of our cultures. Personal thoughts about death alternated with accounts of rituals and funeral ceremonies in Sweden and in Africa. There was so much to think about, so much to discuss! When, in due course, we dispersed, I felt that I had participated in a remarkable event. This was something that I wanted to continue working with.» (Anna Westholm, Gävleborg County Museum, Gävle, Sweden. Läddikan 2/1993)

The Swedish National ICOM committee initiated the meeting in 1989 . We wanted to do something, together with colleagues from other cultures, to develop museums, their role and activities in a particular society. When we met for the first time we did not know much more than this. Should we discuss principles for conservation, policy for collecting or marketing?

We chose to start by creating greater 
understanding among ourselves and others, by meeting and discussing with

DEATH - a boundary, not an ending?

Death unites and affects us all, regardless of our culture, religion and living conditions.

Working on the theme of DEATH, we talked, sang, argued, read, spoke about ourselves.

We pondered long, built a model, marvelling, laughing, crying, consoling, dining, listening, sharing, learning and talking... What came of it all? An exhibition, a poem, a performance.

(Margareta Ekarv, Stockholm, Sweden, 1992 Text to the exhibition "Sharing Ideas") each other, by doing something together.

This programme of cooperation between Swedish and African museums does not represent an innovation in terms of bilateral cooperation. Its uniqueness, however, lies in the way the cooperation is being organized. The themes of the programme were made the subject of preliminary discussions with all possible partners in the project. This has been one of the rare occasions in which professional African museum personnel have been involved right from the start in a project of cultural cooperation even before the details of the project were effectively finalized. (Jean-Aimée Rakatoarisoa, Museum of Art and Archaeology, Antananarivo, Madagascar. SAMP Report 1984-92, 1992)

\section{THE OBJECT}

...The essential function fulfilled by the museum is that of removing the patrimony from physical degradation and oblivion, of making it last for ever and of immortalizing it in memory. In other words, it is the expression of a process of mourning and acts as a mausoleum erected in memory of societies offered on the altar of modernity. (Marc Maure, Le Paysan et le Viking au musée)

We discuss the object and its survival as part of a museum collection. How much should it be shown, used, cared for and restored? How should it be used in research, in exhibitions and in educational programmes? How much can be spent on preserving it? How can we replace it? What is specific to the original object?

These questions should be addressed in consideration of why the museum's collection exists, for what purpose and for whom. Often we take as our point of 
departure for discussion the views and thought of the museum staff. Where are the users? We museum staffs and professionals are users, but so too are researchers, decision-makers, previous owners of the museum's objects, the culturally-linked general public and visitors from other cultures. Who is in charge of a museum's collections?

\section{Objects - museum objects and others}

...In Africa the mask is not an art object one has on the wall to decorate a room. The mask is a living object. If one takes the object away from its ritual and cultural context one takes away its life... (Mwambayi Kalengayi, Zaire, SAMP Report 198492, 1992)

In Sweden we do not express ourselves in the same way but we are in agreement that an object gains a different value when it becomes a museum object, a different significance and that it irretrievably loses its previous identity. An identity that can be preserved in various ways with additional information and which, more or less completely, can be recreated in the new context. A museum object achieves a new identity depending on the context in which it is used.

...Why should I go to a museum, a young Nigerian asked, when I have been raised among these things in the reliquaries of my village? (A. Decker, Beaux Arts No.88, March 1991)

The question opens up a discussion about the attraction of what is common and what is unusual. At a local museum in Sweden, an exhibition of 'embroidered Christmas tapestries' attracted a large number of visitors. Many of the visitors had lent a Christmas tapestry to the museum. People came to look at their own tapestries in a different context. The museum had given Christmas tapestries a new status, a superior cultural value. It is no longer 'a Christmas tapestry' that one looks at but 'my Christmas tapestry at the museum'. Am I, perhaps, exhibiting "myself»?

It is important to know who is responsible for choosing what is to be exhibited and who has decided how it is to be shown. These individuals shoulder a great responsibility, both regarding those who donate objects to the museum and those who see the object in the museum.

Such questions are raised in documenting our own time. When museum staff have made a selection of what should be collected, this can be complemented with things that those interviewed themselves select. The museum staff's requirement that there be a representative collection is complemented by the personally charged objects of the interviewed people.

An interesting collecting project has been undertaken by the artist Boltansky with his installation Norra Förstadsgatan commissioned by Konstmuseet in Malmö. Those living on the street were enabled to exhibit one object each in showcases in the museum. The complete installation was donated to the museum and all the cases with their objects have now become a museum collection. Is this how museum collections of the future will be made?

...the objects would remain in the possession of their users. Each ecomuseum would have to take responsibility for all the objects, rites and signs, and events which take place within its territory... (A.O. 
Konaré, Ecomuseums for the Sahel. MUSEUM 139, 1983)

Should museum collections be located at a museum or outside the institution? Should museum collections consist of the collections of private specialists/fanatics, of what researchers or museum staff select or of what a group chosen by the museum decides?

\section{SAMP and the museum collections}

There has been no methodological discussion within the programme about collections. We all seem to work from habit and protect ourselves from new ideas, perhaps from thinking altogether. We speak of the object's significance for cultural survival and change, in creating a sense of identity and of the importance of an object being preserved, of eternity.

Should museums stop collecting objects and, instead, collect documentation written, oral, pictorial, moving - about the objects in their context; how they were made, how they were used, how they have survived and been preserved? If objects are still to be collected, what objects and how are they to be preserved? Who best preserves the object and who makes it available, the museum or the people?

We have a tendency to look for one, and only one solution to problems. This becomes clear in discussion with colleagues from a different culture.

\section{No collecting projects \\ under the auspices of SAMP}

Is it not collecting when the Gävle muse$u m$ produces an exhibition and purchases objects in Zambia for the exhibition? If there has been no prior discussion, an analysis should be undertaken afterwards in dialogue between the museums of what one has chosen, of how and why it was chosen. What happens to the purchases? Will they become part of the Swedish museum's collections or of the African museum's? Will the objects be preserved or will they 'disappear'? A follow-up would increase our professionality.

The Gävle museum had a clearly formulated goal for the collecting. Personal and recognizable everyday objects were to be collected. The selection criteria were decided having regard to a Swedish cultural context and for a Swedish museum public. This was a clear and carefully thought-out policy which produced the desired result in Gävle.

By analyzing our methods of working we can increase our understanding. Perhaps we should increase our understanding further if the equivalent task were conducted by a colleague at the twin museum in Zambia. The colleague defines a subject, not necessarily the same subject, and the collection is made in Sweden by the African colleague. It is likely that the approach would be a different one.

Have we succeeded in creating the necessary mutual confidence in our professional dialogue to allow such an initiative to be carried out within SAMP? So far this has not been the case and I believe that this depends on the fact that we have recognized, but not stated, behavioral patterns that discourage such confidence. Do we really want to interrupt this pattern? It is only when we have done so that we can enjoy fruitful discussions and other results that develop the museums in all cultures. 


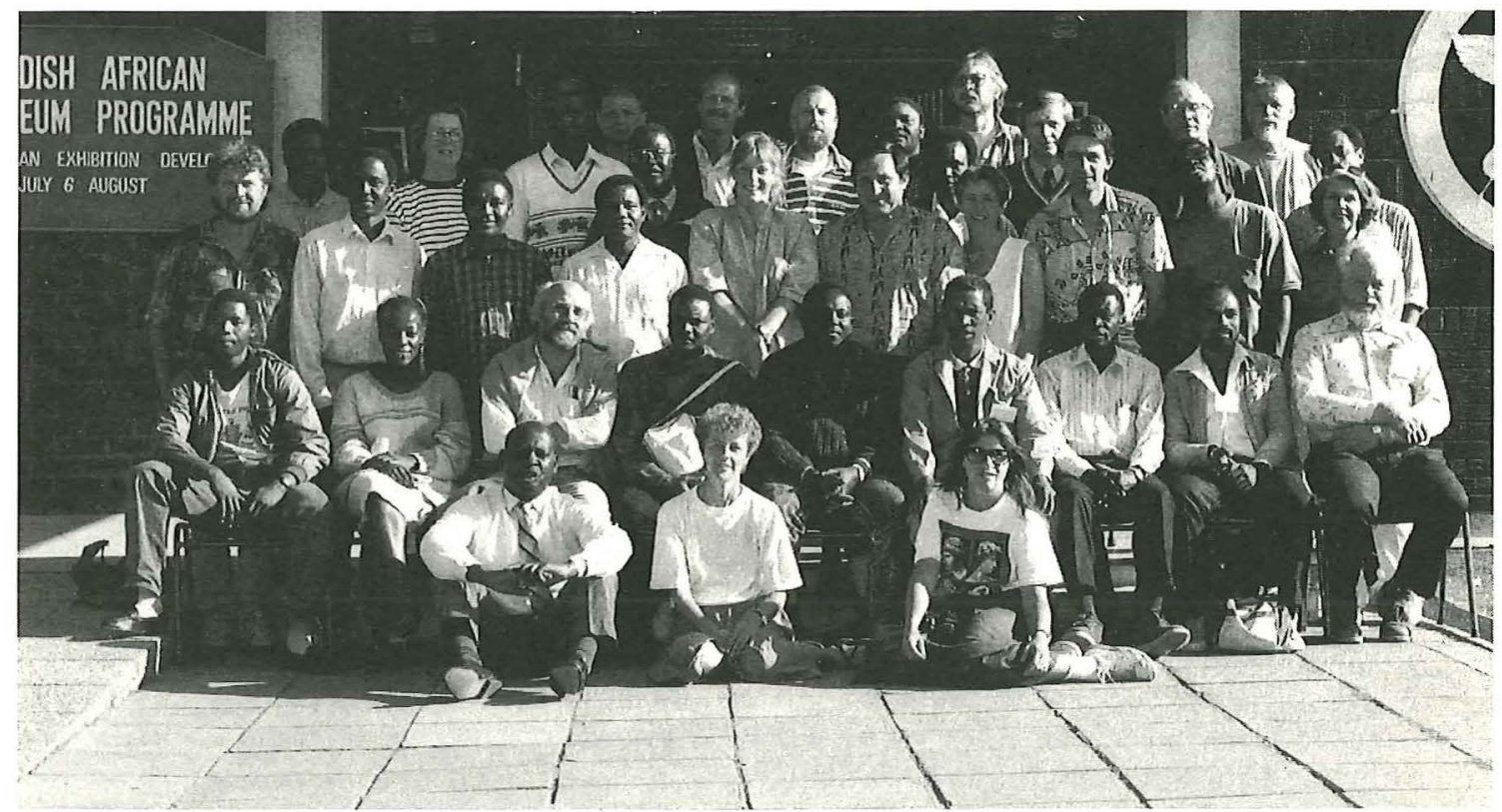

Workshop at the Mutare Museum, Zimbabwe 1991. Photo: Bo Niklasson, Bohusläns museum, Udevalla, Sweden.

\section{LANGUAGE}

...Is it normal that museums, which above all other institutions, are involved in the preservation of cultural identities, should be concerned so little with national languages when these are as much the products, the carrier and the expressions of cultures, as they are the irreplaceable keys to understanding cultural identities and traditions in all their historical complexity and their dynamics...? (Claude Ardouin, 'What Museums for Africa?' 1992)

The question that Claude Ardouin poses is relevant in Sweden too. How do we use the language as a cultural mediator in our museums? In Sweden we have one national language, Swedish, but we have several ways of using the language. Besides oral and written, we have different linguistic genres. We are conscious of this when we produce printed materials. We do not write in the same way for an exhibition catalogue, an informative leaflet about the museum, educational materials for a school class or an article in a learned journal. Do we conduct such a spontaneous analysis of the linguistic form of each exhibition?

It is important to distinguish between understanding a text and comprehending its nuances. The museum needs to ensure that visitors can understand what is written by the museum, but the museum also has a duty to waken the visitors' interest in the richness of the language.

...the use of national languages in museum programmes are rarely taken into consideration in practice, in the planning of exhibitions and educati- 
onal programmes...to understand exhibitions and educational programmes, the visitor should be preferably literate in the official language... (Claude Adouin, 'What Museums for Africa?' 1992)

The linguistic question has come up in Sweden when there has been a desire to address a special group of tourists, necessitating texts in English and Japanese, for example. Certain museums have exhibition texts and informative materials in other languages such as Finnish and Serbo-Croat because there are many immigrants from these countries in the museum's area.

...The non-use of national languages seriously hinders the establishment of communication between the museums and a large section of the national public. Since the national languages are still widely used in oral form, it is essential to develop appropriate methods of communication which do not give predominance to the written word, or which at least use it in combination with the spoken word and with images...In a multilingual society the use of national languages in museums is somewhat delicate. However, this situation should not lead to the easy solution of adopting exclusive use of the official European language... (Claude Ardouin, 'What Museums for Africa?' 1992)

\section{SAMP and language}

We have decided, within the project, that language should not be a barrier to participation. For that reason we have colleagues from countries with French, English and Portuguese as their official languages. But in both Swedish and African museums we have staff who only speak their national language and who have taken part in the project. This creates problems but the common professional back- ground can, to an extent, bridge such problems.

One must always reckon on it taking time to achieve understanding when people do not speak the same language. I think that linguistic barriers can sometimes be helpful in ensuring that things do not progress too quickly in the belief that there is mutual understanding.

In Sweden we initiated a narrative programme with the theatrical performer Mwambayi Kalengayi from Zaire and the Swedish actor Anders Lönnbro. Kalengayi spoke Swahili and Lingala as well as French while his shadow narrated in Swedish. The value of hearing the tales in their original languages cannot be overemphasized. A degree of comprehension was communicated in spite of the lack of literal understanding. Sound, actions and context reinforced the story in a way different from a mere Swedish translation and interpretation. The performances were a great success. There are plans for a Swedish tour in Zaire with Kalengayi as interpreter to the languages spoken in the districts. As yet the plans have not been carried out.

It is interesting and important to reverse the situation and see what happens. Will we not otherwise find ourselves in a fragmentary analysis with an experience strongly coloured by the charm of the exotic?

The exhibition Sharing Ideas shows photographs from the programme's two joint meetings in 1989 and 1991. Right from the start, texts for the exhibition were produced in Swedish, English and French. In Sweden the exhibition was distributed with the Swedish texts and in Africa with both English and French texts.

It was only in due course that we thought of working on the texts. Every 
Swedish museum was asked if it could commission an author from the district to write new texts for the exhibition while it was being shown in their museum.

This was in order to achieve a new interpretation by someone who had seen the exhibition and wrote what she/he thought to be necessary. Rolf Edberg wrote texts when the exhibition was in Karlstad, Värmland and Stig Gålök from Norway wrote texts at the behest of the museum in Jokkmokk.

In Africa the task was somewhat different. The museums were asked whether they would translate the texts to one or more other languages and whether, besides, they could commission new texts during the duration of the exhibition. This resulted in texts translated into Swahili, Malagasy, Lozi and Tonga. There was a new text only in Malagasy.

In several countries visitors to the exhibition were guided by museum lecturers speaking various national languages. It is important to remember that we only worked with the written texts. In many cases it is inordinately much more important to strengthen the possibilities of providing oral texts in guidings, narrative performances and theatrical productions.

At the exhibition course in Zimbabwe in 1991 texts and language were discussed. The text group worked with texts in English, Shona and Ndebele. Discussion was intense and there were many different opinions. What was the goal of the museum in writing texts only in English or only in Ndebele? Or alternatively if the exhibition was provided with texts in all three languages?

The twin museums have produced exhibitions and printed materials together. All the material has been written and printed in the countries' official languages. Is it not essential to discuss the problem of language in relation to the defined target group for each activity? If one produces an exhibition aimed at schoolchildren in some distant part of northern Kenya should the texts not be written in the language that the children have grown up with? This makes more work during production but results, one hopes, in a more meaningful and lasting result.

If one is to create awareness of environmental problems in everyday life by means of a video film should not the recording be done in several languages? Women who talk about their lives in From birth to marriage in a documentation project in Zambia speak Lozi and the interviews are written out in Lozi with an English translation. In this way the material is preserved, in written form, in several languages which makes it more usable.

I find the problem of language missing from the project. This is also true of projects carried out in Sweden. Was there any text or recorded sound from Zambia in the exhibition about Zambia in Gävle? Would this have added anything to the exhibition?

It is important that we use new technology for developing language in museums. But it is equally important that people are able to participate. The individual with the spoken word is far and away the best cultural mediator. A Zambian museum lecturer and a Kenyan lecturer in music give a much richer picture to a Swedish school class than does their Swedish colleague talking about the same subject. The same thing applies to a Swedish music lecturer in Zambia with a Zambian collea- 
88 gue. We have yet to see, within the programme, a Kenyan music lecturer act as guide at an exhibition in Namibia or on Madagascar.

\section{ILLICIT TRAFFIC AND CULTURAL PROPERTY}

...Looting in Africa constitutes one of the contributions to the large effort undertaken by museum professionals in the fight against illicit traffic of cultural property...Crimes against cultural property and natural heritage involve not only looting of archeological sites, but also the theft of artifacts from museums and smuggling of art objects as well as pillaging of natural sites carried out in various circumstances as shown in this publication... (M. Mukela, S. Tshiluila, 'One hundred missing objects' 1994)

Colleagues at museums in Africa are working to spread knowledge of the continuing impoverishment of the national cultural heritage. The situation is complex and can only be solved with local, regional and international cooperation.

A number of measures have been taken following the ICOM meeting in Benin, Ghana and Togo in 1991. In conjunction with two regional seminars on Illicit traffic of cultural property an inventory of national legislation was undertaken and the legal measures taken were studied. The seminars took place in 1993 and 1994 in Arusha, Tanzania and in Bamako, Mali respectively. The meetings gathered together museum experts, police and customs officials from the invited countries. In many instances this was the first time that the officials concerned had met. The results of the seminars will shortly be published by ICOM. These seminars have, at the instigation of museum experts, in many cases been followed up by national seminars.

ICOM has also published Looting in Africa in the series One hundred missing objects. The book has resulted in a number of stolen African objects being localized in Europe. In the task of recovering the objects, attention has been paid to the owner countries' need of legal assistance and financial support.

Another project that started after the 1991 meeting is Standardisation of museum inventories. Museums throughout the world need modern, updated instruments for identifying museum objects. The project directly involves six museums throughout the African continent. Each of the museums also has a regional publicity and training scheme attached to the project. Increased knowledge of the museum's collections is created and a network for African museums is strengthened.

Faced with the deep seriousness with which our African colleagues are working on the preservation of their cultural heritage we European colleagues find ourselves in an embarrassing situation. How can we museum professionals speak in favour of such measures and even, in some instances, support them financially at the same time as our respective countries maintain a very low profile, if not complete silence, on this issue? UNESCO's 1970 Convention on the means of prohibiting and preventing the illicit import, export and transfer of ownership of cultural property has still not been ratified by a large number of European countries, including the Nordic countries and the former colonial powers.

The official aid policy of our countries speaks of the importance of supporting recipient countries in their efforts to 
strengthen their cultural identity. Donors are positive to cultural projects. But where is the will to follow them up? Where is the possibility of discussing solutions to stop impoverishment of national cultural heritages on account of war and other catastrophes as well as economic advantage?

It is no longer sufficient to speak of poor climatic conditions, lack of money and interest and the absence of professional direction of the African museums. The situation is different to-day. It is difficult for the Swedish ICOM and professional Swedish museum staff to work internationally with the ambiguous position that we presently communicate.

\section{MUSEUM}

...Inside the main hut is a traditional umsamo, museum, where solemn articles of a traditional nature are kept. The Siswati word umsamo is not a translation of the English word museum. Neither is museum a translation of umsamo. The English and the Swazi only came into contact in the 19th century. Long before they met, the Swazi developed the idea of preserving and conserving artefacts of historical importance at places known as umsamo... (Rosemary Andrade, SAMP Report 1984-92, 1992)

At the 1992 ICOM General Conference in Quebec, Canada Hughes de Varine presented his view of the museum to-day. $\mathrm{He}$ speaks of two groups of museums: the large international interdisciplinary museums in the major cities of the northern hemisphere with millions of visitors, mostly tourists; and the small museums in which citizens are both the object and the subject, museums in cultural environments with oral traditions, museums that function as cultural centres for local develop- ment. He warns that the former group can 89 dominate the second group and points out that the first group cannot act as models for the latter group. Hughes de Varine underlines that the museums must define their roles and aims and become tools for development. The demand for this has to come from outside if anything is to be achieved, he maintains.

"Yes, a museum is useful!» says Harry Leyten from Toopen's museum in the Netherlands at a museum meeting in southern Africa, SADCAMM's general conference in September 1993. Leyten, too, divides museums into two groups. Museums in large cities that can be élite museums for diplomats or national museums symbolic of unity. Museums can also be neighbourhood or district museums such as community centres or country museums that help the populace to adjust to continuing change while maintaining their cultural identity.

Another voice in the discussion on the role of museums is that of Lars-Olof Edström, Swedish ambassador and aid expert with an interest in cultural matters:

...Interaction and interdependence should be a motto for a museum. There are some crucial features that today are seen as being especially significant for a dynamic and positive development in most environments: Institutions comprising norms, values and attitudes that permeate society, but also legal and other structures. Democratic values and attitudes, development means enlarging people's choices. Gender equality is an imperative also for development and can be systematically furthered by museums. Poverty alleviation is necessary, the improvements must be seen to take place for more than only an élite, this should be illustrated and a discussion initiated by the museum. 
ELISABET OLOFSSON

90 These different activities all require that museums are prepared to interact with the society of which they are a part, to demonstrate how relevant much in the museums is to the everyday world of the present, to start and participate in a dialogue with the community, a give and take on both sides. (L.O. Edström, SAMP Newsletter 1994)

Among our colleagues in Africa, discussion about museums and their role in society is lively. The major meeting for the whole continent's museum professionals which took place in 1991 was a unique opportunity for exchanging experiences, ideas and problems.

...there are thousands of people who work in Africa's museums and who care deeply about the contributions that museums can make to Africa's future. They are aware of the changes that have to be made if African museums are to move beyond a merely custodial role and become significant agents for public education. (Philip L. Ravenhill, 'What museums for Africa?' Museums News, April/March 1992)

There were many and differing views and discussions were lively. Differences are large, which is natural in that we are speaking of a whole continent with some seventy countries and with a large number of cultural zones. It is really not possible to say anything of museums in Africa in general since such universal statements are unusable in a discussion.

Alpha Oumar Konaré, Mali, former president of ICOM, opened the 1991 meeting with the following reflections on the situation of African museums:

...It seems time to eliminate the Western model for museums in Africa so that new methods for the preservation and promotion of Africa's cultural heritage can be allowed to flourish. There is a triple challenge of democratization, decentralization and integration. Democratization is to be achieved through greater participation in the direction, management and staffing of museums. The museums must speak various national languages and be open to science and technology. Decentralization: we mean the creation of regional museums left in the hands of the local inhabitants. Integration: we advocate the endorsement of homogeneous and dynamic regional groups. (A.O. Konaré 'What Museums for Africa?' 1992)

\section{SAMP and the museum}

Perhaps it is the expression whe who walks alone gets lost» that shows us the way to new and more suitable forms for the museum as an institution in to-day's society. "Exchange of experiences and views are indispensable in the development of this new museum", someone has claimed.

Can the museum be reformed from within or must the ideas and the demand for change come from outside? Characteristic of SAMP's method of working is influencing the museum's total organization and all categories of staff. This means that projects often breach the institution's internal departmental boundaries and other invisible divisions which can cause difficulties.

We have chosen to let different types of museums take part in the programme in order, if possible, to broaden discussion. This is why there are museums of anthropology, natural history, history and art participating. The history of the museums varies. Of the Swedish museums participating, the oldest was founded in 1739 , four others have been going since the 1800 s while the youngest opened in 1984. The 
oldest participating African museum opened in 1931 and the youngest in 1980 .

The museums are to be found in large cities and small towns and they differ as to organizational structure. All these differences were desired, but have they led to the desired result; i.e., have they facilitated change and the exchange of ideas?

I now realize that we had hopes of discovering a goldmine of ideas, curiosity and desire for change in Africa. Is this the usual colonial reflex of wishing to find what one lacks or of wishing that others will do what it is difficult to do at home?

To-day we experience, quite independent of whether we as professionally trained museum staff are at an African or a Swedish museum, that we relate in a similarly professional manner to the museum and to objects. I think that this is the result of us all having been trained in the same academic tradition and, of largely sharing the same museology.

Will we see a difference when African museologists are trained in Africa by native teachers? Will we see a difference when we allow our thinking to develop in a dialogue between our local cultural and intellectual base and our global professional contacts, as within SAMP?

\section{EXCHANGE FOR CHANGE}

...Interaction and cooperation across frontiers of various kinds presupposes actors with a reasonably clear sense of identity. (L.O. Edström, SAMP Newsletter 1994)

...Every visit outside one's own country puts into perspective the society in which one has grown up, every contact over cultural divides is a review of one's own history. To create understanding, con- tacts over cultural divides must be rooted in reality. In the world which is so clearly divided into 'we' and 'them' we may need a cultural contact that is more rooted in reality. In cultural contacts we have to look and listen, to have our eyes and ears open. There is also an important element of reciprocity... (Anna Wieslander 'Moto Moto meetings in Zambia and Zimbabwe' 1993)

When the Swedish ICOM started the Swedish-African Museum Programme in 1984, Kulturhuset in Stockholm had, over an extended period, been working on a major project of exhibitions, performances and lectures on Africa. According to Beate Sydhoff, director of Kulturhuset at the time, the intention was, by means of the exchanges, to eradicate the antiquated notion of 'ethnography' which had previously been part of all the earlier contacts between the countries.

The exchange that was started within the Swedish ICOM project was formalized in 1989 and, from the start, worked on many levels.

...cross-border cooperation not only between regions and nations, but also between various types of museums and between different categories of personnel within museums... (Ulla Keding Olofsson, SAMP Report 1984-1992, 1992)

\section{SAMP experiences}

It is essential that museums participating in the programme are active over an extended period. For this reason it is essential that both the museum's board and the whole staff actively support participation. Swedish museum boards are changed regularly which means that information about the museum's undertakings 
92 is continually subject to discussion.

Many of the participating Swedish museums are regional museums, whose traditional field of operation is the län or 'county'. Although Sweden is a multicultural society to-day, it can be difficult to win sympathy for participation in an international programme like SAMP.

Three directors of regional museums in Sweden on their participation in SAMP:

...Museums need to avoid looking inwards and feeling self-sufficient. In general we work in a very restricted geographical area and the international contacts that can generate new ideas and new knowledge are all the more important. Contact with African museums has provided us with new perspectives on our own activities. (Monika Minnhagen-Alvsten, 'Ideas about SAMP' 1993)

...As far as the personnel of my museum is concerned, I want to see the project widening their humanistic perspective, thus working against the ethnic prejudices that can create conflict. It is also useful to have a different kind of measure with which to re-evaluate our philosophy in the museum field. The SAMP does provide a vital counterbalance to an excessively European outlook... (Gunnar Lindqvist 'Ideas about SAMP' 1993)

...SAMP functions as a sort of further-training programme and it is difficult to imagine a more stimulating programme for people working in the cultural sector than one whose aim is to open doors to the outside world... (Hans Manneby 'Ideas about SAMP' 1993)

Collaboration between a. Swedish and an African museum brings problems at various levels. The large geographic distance is the outer and first barrier but perhaps not the largest one. Swedish museums have no expe- rience of practical cooperation with a museum in another country. Previous international contacts have largely been the preserve of the major museums in the capital.

Activities at Swedish museums are, nowadays, mainly organized as projects with their own budget and staff. Projects have often to be completed in a relatively short space of time. This method of working has reinforced our need to see results within a limited time.

In collaborating with a twin museum in an African country it has proved necessary to work in a different manner. The goal is not, in the first instance, rapid concrete results. Five years have passed since the programme started with concrete activities and that period has been necessary for establishing a base for extended collaboration. Two African museum directors describe the conditions for exchange thus:

...Differences whether of magnitude or quality of any twinned museums are important factors to the kind and form of successive collaboration and exchange. The framework of collaboration has to take into account the differences and strengths of the two museums.

Exchange of staff that involves different disciplines or specialities is very important to all twins and should include not only the directors but also technicians, curators and museum education staff. For twins to succeed in their collaboration it needs commitment and understanding. Collaboration must be based on the things that the museums involved are interested in. (Paul Msemwa, SAMP Newsletter 1994)

...Collaboration implies two or more parties working together to achieve a given objective that will be of value to the parties concerned. To find common ground has been a slow and difficult process. 
Cultural barriers have inhibited progress. And the unequal level of economic and social development of the two countries has been a hindrance in that our needs are dissimilar. Most serious bottleneck lies in the stereotyped notion that the relationship would be in the form of an aid programme. This view can be found in both African and Swedish museums. A lasting collaboration must be based on mutual respect, on a relationship in which neither of the parties expects to receive favours from the
Map showing museums and contacts with Samp. (Carina Nilsson, Stockholm) From Swedish-African Museum Programme Newsletter November, 1993




94 other party... (Manyando Mukela, 'Ideas about SAMP' 1993)

The exchange programme is organized by the professional museum organization ICOM. We can consider it as a possibility of developing our profession and of working for recognition of the museum's status. Regular information about what we are doing is important. Information should be aimed both outwards at decision-makers and the public and inwards at museum boards and staff. Opportunities and needs differ and there are, therefore, many ways of working. We let every participant work in their own way but try to spread information as to how everyone works in order to offer new tools to each other.

...The programme has allowed us to demonstrate to the Madagascan authorities that the preoccupations of our museum have international dimensions... (J.A. Rakotoarisoa, 'Ideas about SAMP', 1993)

Experiences and methods of working are many. Some museums have already realized projects at both the African and the Swedish museum. This is the case with the Bohus County Museum in Uddevalla, Sweden and the Kisumu Museum in Kenya. At both museums there have been exhibition projects which have also involved training, seminars and activities aimed at visitors.

Teresia N'ganga, following experience of working at the Kenyan museum, says of the project: "...Cooperation and sharing each other's ideas is one way foreward but for that relationship to develop we have to work together.» Her colleague James Maikweki has previous experience of international exchanges and he analyzes what is new to him in working with Swedish colleagues

...I think the success is a result of sharing work and ideas and putting them into practice. It is mainly because the Swedes came to work together with our people. They did not come as bosses to issue instructions but were involved in the whole project.

The exhibition The first steps, mankind's journey from his African origins opened in Uddevalla in October 1994. Two Kenyan museum lecturers acted as guides at the exhibition in Uddevalla for a number of weeks. The director of the museum, Hans Manneby, comments on the aim of the exhibition: "The aim was to give visitors a picture of our earliest history and with it a truer perspective on our own society.»

In the summer of 1993 the Village Museum from Tanzania visited its Swedish twin Skansen in Stockholm. The dance troupe from the Village Museum danced and craftsmen worked publicly for a number of days in August. The director of the Tanzanian museum expressed his thoughts:

As a result, more Swedish people were able to see Tanzanian artists performing live traditional dances and the opportunity allowed the audience to contextualize musical instruments and craft objects observed displayed in museums. For Skansen the exhibit was an opportunity to show the public the involvement of Skansen in international programmes. (Paul Msemwa, SAMP Newsletter 1994)

There are ideas for projects and commitment to the programme at the museums to-day. New initiatives and ideas from outside are presented both for African and Swedish museums and are attractive. I consider it quite normal but it is, never- 
theless, problematic, when we all know that change and development take time and that we must, therefore, work for a continued commitment to the programme. Input need not be equally intensive every year but there must always be a desire to keep the commitment alive.

...If the various projects are not to remain single events but part of an ongoing process, it is essential that the twinned museums take responsibility for the programme... (Desirée Edmar 'Ideas about SAMP' 1993)

...SAMP provides the individual museums with a framework of practical and financial support and the consciousness that one is part of a larger community of collaborating museums strengthens the sense of responsibility of individual museums and helps us to achieve results. (Hans Manneby, 'Ideas about SAMP', 1993)

After five years of work, 85 Swedish and 75 African museum employees have, in various ways, been engaged in the project. The exchange of ideas and the discussions have been lively. Are we Swedes to create Africa's model museum? Are the Africans to create Sweden's model museum?

Perhaps this would be worth working with, perhaps something fuitful. We are ever ready to discuss what sort of museum suits Africa but are we prepared to discuss as openly what sort of museum suits Sweden? We are probably best, each of us, at seeing what sort of museum fits our context but we see this more clearly after discussion with others and after seeing things from without. For this reason all contacts with the world at large are important and networks like those within SAMP are essential to museum development.
...The exchanges of ideas have not only brought us closer to our twinned museum but have also led to closer collaboration between museums within Sweden and Africa respectively. The SAMP project has opened up an avenue of experience that has contributed to the socio-cultural development of our human resources and our institutions... (Rosemary Andrade, 'Ideas about SAMP' 1993)

...this being the first time that such a large group of Namibian museum workers have travelled abroad together, to meet and exchange ideas with counterparts from other African countries, Madagascar, Sweden. The development of links such as that of the SAMP twinships, has helped to underline the importance of museums, indeed the associated psychological effect is very important in the current socio-economic climate, where we continually need to make our politicians and administrative authorities aware of the very idea of museums and their fundamental importance to society, museums play a hugely important role in public education, and providing insights to the changing world we live in. (Joris Komen, SAMP Newsletter 1994)

\section{NOTES}

SAMP = Swedish-African Museum Programme. An exchange programme between one Swedish and one African Museum, twins based on mutual exchange and initiated by the Swedish ICOM committee.

SADCAMM $=$ Southern African Development Community Association of Museums and Monuments 
ELISABET OLOFSSON

96

REFERENCES

Beaux-Arts No. 88, March 1991

Ideas about SAMP, 1993. The Swedish ICOM committee, ISBN 91-630-1966-3

Läddikan 2/1993, Gävleborg County Museum

Maure, Marc, Le Paysan et le Viking au musée,

Tours December 1993

The Moto Moto meetings in Zambia and Zimbabwe

1993, Gävleborg County Museum

MUSEUM, 148/1985

Museum News, March/April 1992

One hundred missing objects, ICOM 1994, ISBN

92-9012-017-7

SAMP Newsletter 1994

SAMP Report 1984-1992, The Swedish ICOM

committee, ISBN 91-630-1216-2

What Museums for Africa? ICOM 1992, ISBN $92-$ 9012-112-2

Elisabet Olofsson has worked at the ATP-museum, Paris, and Musée de Rennes, France; at the regional museum of Värmland, Karlstad, the municipal museum of Lidköping, the Postmuseum and Wasa museum in Stockholm. She serves as coordinator for the Swedish-African Museum programme.

Adr: Katarina Bangata 51, S-11619 Stockholm

Fax $+46-(0) 8-7148123$ 